\title{
Optimal distance of an external focus of attention in standing long jump performance of athletes
}

\author{
Lotfi Gh. ${ }^{\mathrm{ABCDE}}$
}

Shahid Rajaee Teacher Training University, Tehran, Iran

Authors' Contribution: A - Study design; B - Data collection; C - Statistical analysis; D - Manuscript Preparation; E - Funds Collection.

\begin{abstract}
Purpose: $\quad$ Recently, studies have shown that an external focus of attention improves the performance of individuals. Some studies have also confirmed the superiority of distances away from body for external focus of attention. The aim of this study was to determine the optimal distance of an external focus of attention when performing athletes' standing long jump.

Material: $\quad 51$ volunteer students $(\mathrm{M}$ age $=23.31 \pm 5.26$ years) were selected as sample. At first all they performed a standing long jump in control status (without instruction for focus of attention). Then in an interpersonal counterbalanced design, a pair of jumps was performed with four different distances of an external focus of attention. These distances included 0.5, 2.5, 4 and 8 meters from the jump start line marked with colored tapes on the ground.

Results: $\quad$ The results showed that having an external focus of attention compare to the control conditions has a significant advantage in the performance of the athlete's standing long jump. Also, the performance of athletes at different distances of an external focus of attention was compared. Results showed that the four-meter distance was significantly better performance than the half-meter distance of an external focus of attention.

Conclusions: $\quad$ Four-meter distance can be introduced as the optimal distance of an external focus of attention in the performance of athletes' standing long jump.

Keywords: $\quad$ students, distance effect, jumping, concentration, environmental cues.
\end{abstract}

\section{Introduction}

The way of using attention is one of the variables affecting performance and learning of motor skills; in recent years, it has attracted the attention of many scholars. In fact, the empirical evidence suggests that the focus of attention during the performance of motor skills may affect the quality of performance [1]. The researchers and in particular, William James explain attention with some of its features such as concentration, focus, and consciousness [2]. Since humans can only process a limited amount of information at any given moment [3], the process of voluntarily paying attention to a specific area of stimuli is called focusing attention.

According to Nideffer's theory (1976), the focusing of attention may take place in two scope (wide versus narrow) and direction (external versus internal) dimensions [4]. The internal focus strategies refer to situations in which one focuses on part of his/her body or movements during performance. On the other hand, the external attention strategies refer to situations in which one pays attention to effects and results of his/her movement at environment [5]. The difference between these attentive strategies is summarized in a few words; however, the different effects of these attention strategies on performance and motor learning are determined [1]. This effect has been shown to increase effectiveness (accuracy and distance) and efficiency (kinetic and kinematic indices) of movements by applying external attention strategies rather than internal attention strategies, regardless of skill level of performers [6]. Singer et al. (1993) showed that in order to achieve higher levels of self-efficiency and consequently, better performance, it is necessary to use the attention instructions which divert learner's attention from physical movements. The focus of attention strategies of Singer

(C) Lotfi Gh., 2018

doi:10.15561/20755279.2018.0304 et al. (1993) emphasizes the importance of avoiding attention from internal dimensions of movement [7]. On the other hand, the empirical research emphasizes on applying external attention strategies rather than internal attention strategies [1].

The benefits of external attention strategies are well described by limited performance hypothesis. Based on this hypothesis, the effort to consciously control the movement as internal focus strategies limits the motor system and prevents from automatic processes which control the movement. Conversely, moving away attention from movement and shifting it to motion effects (external attention strategies) allows the system to achieve selforganization through greater involvement in automated processing processes; this may result in improved performance and movement [8, 9]. The constraintdriven approach is another view which is provided about underlying mechanisms of external attention. According to this approach, the external focus of attention facilitates the fitting of environmental information, promotes the dynamic characteristics of self-organizing movement in motor system, and subsequently, improves motor performance. In other words, the focus on effects of moving in environment gives direction to search processes of performance factors and helps performer to search and discover specific environmental information which are needed to develop the pairing of perception and practice and self-organize task performance constraints [10]. The optimal motor learning theory of Wolf and Lewthwaite (2016) argues that the motivation and attention factors improve pairing of goals with practice and lead to improved performance and learning of movement. According to this theory, if external attention strategies are used, the motor and cognitive systems of performers may move in right direction and avoid from self-conflicts and unrelated attention focus conditions; this may finally 
lead to stronger consolidation process and optimal learning [11].

Several studies have shown that the use of instructions which attract the attention of performer to out of his/ her body may improve motion skills learning and performance in comparison with instructions which draw attention of individual to body and its organs. Some tasks were jump height [12], dart throwing [13], goal directed ball throwing [14], hitting the golf ball [15], tennis [16] and throwing accuracy [17]. Depending on type of motor tasks and skill level of performers, the effects of factors will be different. All these categories of attention will be involved in both obvious and hidden control processes to lead to an optimal performance. In other words, different attention strategies may be effective in choosing different types of obvious or hidden control processes [18].

Although the strategy of focus of attention in performance of tasks such as standing long jump is confirmed to be external, the optimal distance of external focus of attention from body is the next question which needs to be investigated. Several studies have investigated the optimal distance of external focus of attention in two states: far from body and near the body. They often have concluded that the external focus of attention at far from body will lead to improved performance [1921]. However, some studies have not seen significant differences between different distances of external focus of attention. For example, Westphal and Porter (2013) showed superiority of external focus of attention to control situation; however, they did not see any difference in three and five meters distances of external focus of attention [22]. Therefore, the skills that do not require movement precision and there is no specific goal for external attention, the attention focus of performer is still questioned. The introduction of optimal distance of external focus of attention may help to better perform the task.

\section{Material and methods}

Participants: Participants consisted of 51 male students (mean age $=23.31 \pm 5.26$ years old, mean height $=$ $181.47 \pm 19.17 \mathrm{~cm}$, and mean weight $=71.73 \pm 10.6$ $\mathrm{kg}$ ) who voluntarily participated in study. They were considered athletes due to at least three years of regular exercise practice. Based on their self-reported forms, the participants did not suffer from any physical and motor limitation or injury and specific disease-causing effects on motor function.

Research Design: In this applied, semi-experimental, field study the participants were asked to warm up for 10 minutes before performing standing long jumps. Then, the correct way of standing long jump performance was reviewed and they were asked to jump twice to measure their jump distance; the best record was recorded as control jump (without focus of attention instruction). Placing one of marked signs on land as external attention focus at jump time, then, the participants performed two jumps at each distance; the longest distance at each external attention focus was recorded as record of that distance. The order of attention focus distances was determined in counterbalance design for each participant to control the effect of order on participants' performance. At the time of changing the distance of external attention focus (after both jumps), one minute rest interval was considered. The external focus of attention sites which were marked with 40-cm long and $5-\mathrm{cm}$ wide tapes on ground were at distance of $0.5,2.5,4$, and 8 meters from jump start line.

Statistical Analysis: The collected data were analyzed using SPSS software, version 21. The mean and standard deviation were used to describe statistically the data. The Excel software was used to create charts. The Shapiro -Wilk test was used to examine data distribution normality and Levene's test was used to study the homogeneity of variances. The inferential statistics included repeated measures and one-way analysis of variance. The significance level in all analyses was considered to be .05 .

\section{Results}

The mean of participants' standing long jump at different attention focuses is summarized in table 1 .

The results of analysis of variance with repeated measures indicated that there was a significant difference between participants' performance under different conditions of attention focus $\left(\mathrm{F}_{(3.025,151.27)}=23.603\right.$, $\mathrm{P}=0.001, \eta 2=0.321$ ). Bonferroni's post-hoc test was used to determine the best distance of external attention focus in performing standing long jump; the results are summarized in table 2.

According to above table, the performance of athletes at all distances of external attention focuses is significantly better than control condition (without attention focus instructions). Also, the performance of athletes in distance of $4 \mathrm{~m}$ from external attention focus is significantly better than $0.5 \mathrm{~m}$ distance. Therefore, it can be said that the 4-meter distance of external attention focus is considered as an optimal distance for performance of standing long jump by athletes; this is displayed in figure 1 .

Table 1: Statistical description of participants' performance at different attention focuses

\begin{tabular}{lll}
\hline Distance of an External Focus of Attention & Mean & Standard Deviation \\
\hline Without Instruction (Control) & 201.27 & 18.886 \\
0.5 M & 208.04 & 18.476 \\
2.5 M & 211.90 & 18.719 \\
M & 212.88 & 17.358 \\
$\mathbf{~ M ~}$ & 210.33 & 18.621 \\
\hline
\end{tabular}


Table 2: Bonferroni test results compared to performance of athletes at different distances of external attention focus

\begin{tabular}{lllll}
\hline $\mathbf{i}$ & $\mathbf{j}$ & Mean Difference (i-j) & Standard Error & Sig \\
\hline \multirow{3}{*}{ Control (Without } & $0.5 \mathrm{M}$ & $-6.765^{*}$ & 1.227 & 0.001 \\
Instruction) & $2.5 \mathrm{M}$ & $-10.627^{*}$ & 1.805 & 0.001 \\
& $4 \mathrm{M}$ & $-11.608^{*}$ & 1.612 & 0.001 \\
& $8 \mathrm{M}$ & $-9.059^{*}$ & 1.163 & 0.001 \\
$\mathbf{0 . 5} \mathbf{M}$ & $2.5 \mathrm{M}$ & 3.863 & 1.342 & 0.059 \\
& $4 \mathrm{M}$ & $-4.843^{*}$ & 1.138 & 0.001 \\
$\mathbf{2 . 5} \mathbf{M}$ & $8 \mathrm{M}$ & -2.294 & 1.185 & 0.586 \\
$\mathbf{4} \mathbf{M}$ & $4 \mathrm{M}$ & -0.980 & 1.365 & 1.000 \\
\end{tabular}

NOTE. i \& j are different distances. * Mean difference is significant at .01 levels

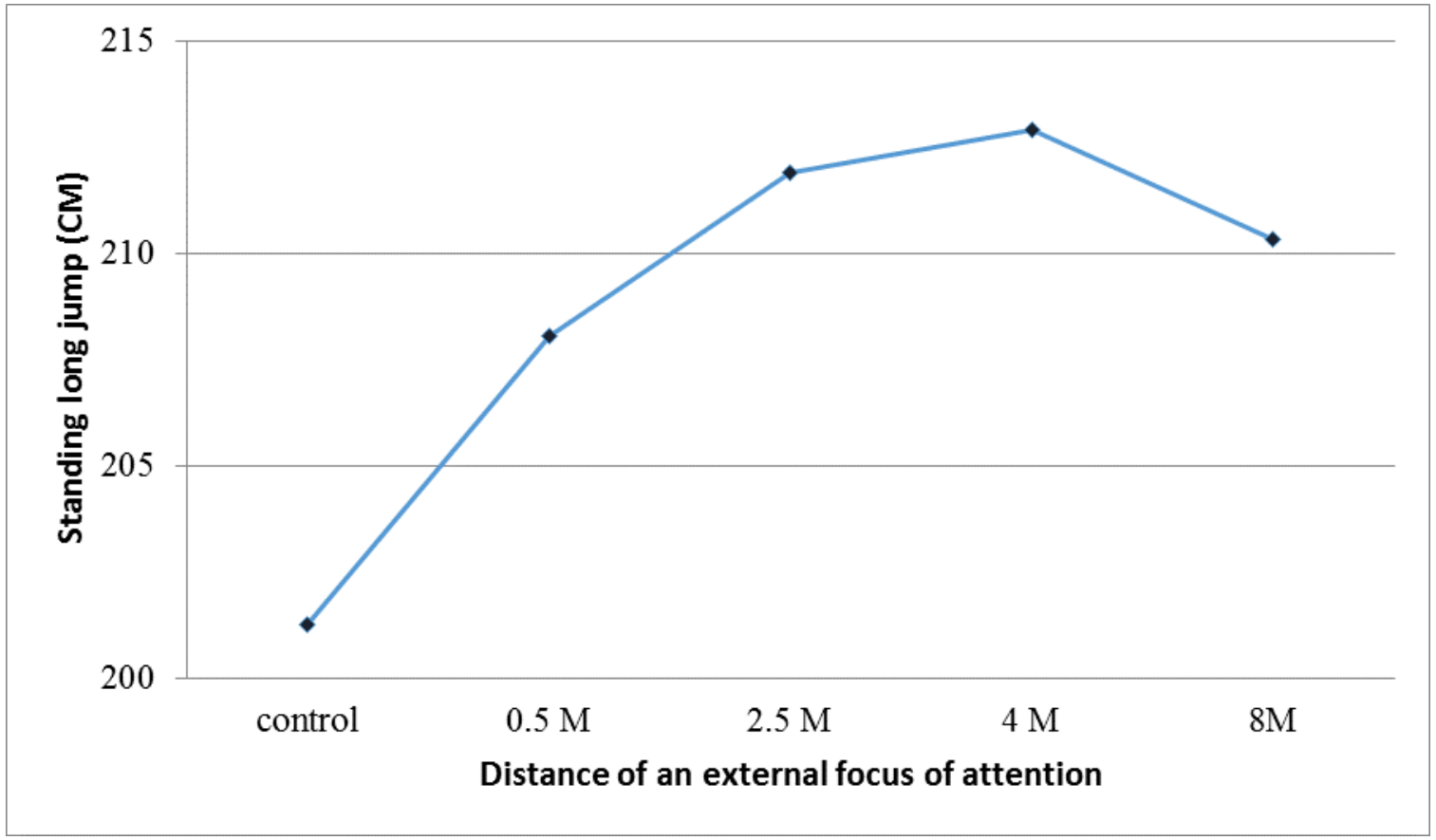

Figure 1: Participants' performance at different conditions of attention focus

\section{Discussion}

The athletes' performance at all distances of external attention focus was significantly better than control condition (without attention focus instructions). The athletes benefited from external attention focus (regardless of attention focus distance) and the lack of attention focus instructions did not weaken performance of athletes; this is consistent with findings of many studies [12, 20-28]. The restricted action hypothesis (Wulf et al.) attributes the supremacy of external focus of attention to diverting attention from motion and shifting it toward motion effects. It argues that this allows the system to involve more in automated processing processes through selforganization and this may improve motor function. The Vance et al.'s theory of efficient muscular activity (2004) studies the difference between various attention focuses at neuromuscular level and argues that the external attention increases recurrent motor units and effective coordination between muscles; thereby, it improves motor function. The findings of this study may be explained using this theory.

Also, the athletes' performance at 4-meter distance from attention focus was significantly better than 0.5 meter distance. Therefore, it can be said that the distance of 4 meter from external focus of attention is an optimal distance for standing long jump performance. Few studies have suggested contradicted results. For example, Asadi et al. (2016) did not report difference in standing long jump performance under far and near external attention focuses [27]. Westphal and Porter (2013) did not report difference in standing long jump performance at three and five meters external attention focus distances [22]. However, Bell and Hardy (2009) regarding golf shot [29], Ahmadi and Borhani (2015) on jump service at volleyball [30], and Porter et al. (2013) regarding standing long jump [21] provided consistent results with findings of this study; they stated that the skilled athletes performed better at far external focus of attention than near external focus of attention. Although this study only defined two 
far and close levels for external focus of attention and did not investigate a range of different distances.

\section{Conclusions}

It is argued that the athletes have better performance at far distance of external focus of attention; however, very far distances ( 8 meters) of external focus of attention may lead to weakened performance. It seems that if focus of athletes' attention in tasks such as standing long jump be chosen to be more far from body so that the landing point is in ambient vision of athlete, he/she will have best performance. Wulf (2013) believes that the distance of focus of attention is directly related to skill level of individuals; the skilled people use far external attention focus strategies more effectively. Therefore new studies should be conducted to introduce the optimal distance of external focus of attention in nonathlete people and compare it with athletes.

\section{Financing}

This work was supported by Shahid Rajaee Teacher Training University under contract number 11537.

\section{Conflict of Interests}

The author declare that there is no conflict of interest regarding the publication of this paper.

\section{References}

1. Wulf G. Attentional focus and motor learning: A review of 15 years. International Review of Sport and Exercise Psychology, 2013; 6: 77-104.

2. James W. Principles of psychology (Vol. 2). New York: Holt; 1890.

3. Schmidt RA, Wrisberg CA. Motor learning and performance: A situation-based learning approach. Human Kinetics; 2008.

4. Nideffer RM. Test of attentional and interpersonal style. Journal of Personality and Social Psychology, 1976; 34: 394-404.

5. Sherwood DE, Lohse KR, Healy AF. Judging joint angles and movement outcome: shifting the focus of attention in dart-throwing. Journal of Experimental Psychology: Human Perception and Performance, 2014; 40(5): 1903-1914.

6. Lohse KR, Wulf G, Lewthwaite R. Attentional focus affects movement efficiency. In: Hodges N, Williams AM. Skill Acquisition in Sport: Research, Theory \& Practice. London: Routledge; 2012.

7. Singer RN, Lidor R, Cauraugh JH. To be aware or not aware? What to think about while learning and performing a motor skill. Sport Psychologist, 1993; 7: 19-19.

8. Wulf $\mathrm{G}$, McNevin $\mathrm{NH}$, Shea $\mathrm{CH}$. The automaticity of complex motor skill learning as a function of attentional focus. Quarterely Journal for Experimental Physiology, 2001; 54: 1143-54.

9. McNevin NH, Shea CH, Wulf G. Increasing the distance of an external focus of attention enhances learning. Psychological Research, 2003; 67: 22-9.

10.Davids K, Button C, \& Bennett S. Dynamics of skill acquisition: A constraints led approach. Champaign, Illinois: Human Kinetics; 2008.

11. Wulf G, \& Lewthwaite R. Optimizing performance through intrinsic motivation and attention for learning: The OPTIMAL theory of motor learning. Psychonomic Bulletin \& Review, 2016; 1-33.

12.Wulf G, Dufek JS, Lozano L, Pettigrew C. Increased jump height and reduced EMG activity with an external focus. Human Movement Science, 2010; 29: 440-448.

13.McKay B, Wulf G. A distal external focus enhances novice dart throwing performance. International Journal of Sport and Exercise Psychology, 2012; 10(2): 149-56.

14.Saemi E, Porter JM, Wulf G, Ghotbi-Varzaneh A, \& Bakhtiari S. Adopting an external focus facilitates motor learning in children with attention deficit and hyperactivity disorder. Kinesiology, 2013; 45: 179-185.

15.An JS, Wulf G, Kim S. Increased carry distance and X-factor stretch in golf through an external focus of attention. Journal of Motor Learning and Development, 2013; 1: 2-11.

16.Hadler R, Chiviacowsky S, Wulf G, Schild JFG. Children's learning of tennis skilled is facilitated by external focus instructions. The Journal of Physical Education, 2014; 20(4): 418-422.

17.Pascua LAM, Wulf G, Lewthwaite R. Additive benefits of external focus and enhanced performance expectancy for motor learning. Journal of Sport Sciences, 2015; 33(1): 5866.

18.Lohse KR. On attentional control: A dimensional framework for attention in expert performance. The Handbook of Sport Expertise, 2015; 38-49.

19.Porter JM, Anton PM, Wu WFW. Increasing the distance of an external focus of attention enhances standing long jump performance. Journal of Strength Conditioning Research, 2012; 26(9): 2389-93.

20.Wu WF, Porter JM, Brown LE. Effects of attentional focus strategies on peak force and performance in the standing long jump. Journal of Strength Conditioning Research, 2012; 26(5):1226-31.

21.Porter JM, Anton PM, Wikoff NM, Ostrowski J B. Instructioning skilled athletes to focus their attention externally at greater distances enhances jumping performance. Journal of Strength Conditioning Research, 2013; 27(8):2073-8.

22. Westphal W, Porter JM. Increasing the distance of an external focus of attention has limited effects on standing long jump performance. International Journal of Exercise Science, 2013; 6(4): 300-9.

23.Vance J, Wulf G, Töllner T, McNevin N, Mercer J. EMG activity as a function of the performer's focus of attention. Journal of Motor Behavior, 2004; 36: 450-459.

24.Zachry T, Wulf G, Mercer J, Bezodis N. Increased movement accuracy and reduced EMG activity as the result of adopting an external focus of attention. Brain Research Bulletin, 2005; 67(4): 304-309.

25.Marchant DC, Clough PJ, Crawshaw M. The effects of attentional focusing strategies on novice dart throwing performance and their task experiences. International Journal of Sport and Exercise Psychology, 2007; 5: 291-303.

26.Zarghami M, Saemi E, Fathi I. External focus of attention enhances discus throwing performance. Kinesiology, 2012; 44(1): 47-51.

27.Asadi A, Farsi AR, Abdoli B. Effect of increasing the distance of an external focus of attention on performance and kinematic of horizontal jump in skilled athletes. Motor Behavior, 2016; 8 (23): 65-78. (In Persian)

28.Abdollahipour R, Nieto MP, Psotta R, Wulf G. External focus 
of attention and autonomy support have additive benefits for more performance in children. Psychology of Sport and Exercise, 2017; 32: 17-24.

29.Bell JJ, \& Hardy J. Effects of attentional focus on skilled performance in golf. Journal of Applied Sport Psychology,
2009; 21(2): 163-177.

30.Ahmadi M, Borhani $\mathrm{H}$. The effects of distance of attentional focus on accuracy, effectiveness and perception of performance in volleyball jump service. Research in Sport Management and Motor Behavior, 2015; 5(9): 21-29. (In Persian)

\section{Information about the author:}

Lotfi Gh.; http://orcid.org/0000-0002-4506-5313; gholamrezalotfi@sru.ac.ir; Shahid Rajaee Teacher Training University; Shahid Rajaee Teacher Training University, Lavizan, Tehran, Iran.

Cite this article as: Lotfi Gh. Optimal distance of an external focus of attention in standing long jump performance of athletes. Physical education of students, 2018;22(3):134-138. doi:10.15561/20755279.2018.0304

The electronic version of this article is the complete one and can be found online at: http://www.sportedu.org.ua/index.php/PES/issue/archive

This is an Open Access article distributed under the terms of the Creative Commons Attribution License, which permits unrestricted use, distribution, and reproduction in any medium, provided the original work is properly cited (http://creativecommons.org/licenses/by/4.0/deed.en).

Received: 12.05.2018

Accepted: 11.06.2018; Published: 27.06.2018 